\title{
Temperature and precipitation changes over the Loess Plateau between 1961 and 2011, based on high-density gauge observations
}

\author{
Qiaohong Sun ${ }^{\mathrm{a}, \mathrm{b}}$, Chiyuan Miao ${ }^{\mathrm{a}, \mathrm{b}, *}$, Qingyun Duan ${ }^{\mathrm{a}, \mathrm{b}}$, Yafeng Wang ${ }^{\mathrm{c}}$ \\ a State Key Laboratory of Earth Surface Processes and Resource Ecology, College of Global Change and Earth System Science, Beijing Normal University, Beijing 100875, PR China \\ b Joint Center for Global Change Studies, Beijing 100875, PR China \\ c State Key Laboratory of Urban and Regional Ecology, Research Center for Eco-environmental Sciences, Chinese Academy of Sciences, P.O. Box 2871, Beijing 100085, PR China
}

\section{A R T I C L E I N F O}

\section{Article history:}

Received 3 March 2015

Received in revised form 7 May 2015

Accepted 15 May 2015

Available online 22 May 2015

\section{Keywords:}

Loess Plateau

climate change

extreme events

Gini coefficient

\begin{abstract}
A B S T R A C T
The Loess Plateau has the most serious soil erosion in China and is the main source of sediment in the Yellow River. In this study, we systematically analyzed the changes in the mean and extreme values for temperature and precipitation over the Loess Plateau between 1961 and 2011, using a gridded dataset with high-density gauge data. Statistically significant positive trends $(p<0.05)$ in the mean, maximum, and minimum temperature values (TM, TX, and TN) were identified in almost all regions. Warming rates increased from the southeast to the northwest of the Loess Plateau for both TM and TN; however, for TX, the greatest warming increases were observed in the southeast region. We also found general decreases in the diurnal temperature range and the number of cold nights and cold days, and increases in the length of the growing season and the number of warm days and warm nights. Moreover, relatively intense changes occurred in the high percentile ranges for both TX and TN. The total amount of precipitation on wet days decreased over a large area of the Loess Plateau, particularly in the southeast region. The inequality in the spread of precipitation over the year (temporal inequality) increased extensively over the past fifty years in the wet region. Approximately $37.60 \%$ of the total area with a reduced amount of precipitation had concurrent decreases in both the frequency and intensity of rainfall. However, approximately $37.20 \%$ of the area with a reduced amount of precipitation had decreases in the frequency but increases in the intensity of rainfall. The proportion of days with light or moderate precipitation was decreased in the wet region which mainly located in the southwest of the Loess Plateau, but there were only minor changes in extreme precipitation events. Overall, when both temperature and precipitation changes were combined, we observed that the southwest of the Loess Plateau has undergone the largest degree of climate change. Consequently, both the ecological environment and local agriculture on the Loess Plateau will suffer increased challenges: the decline in water availability will lead to more frequent droughts, yet the risk of flood and soil erosion from extreme precipitation events will not be reduced.
\end{abstract}

(c) 2015 Elsevier B.V. All rights reserved.

\section{Introduction}

The Loess Plateau $\left(35-41^{\circ} \mathrm{N}, 102-114^{\circ} \mathrm{E}\right)$ is situated in the upper and middle reaches of the Yellow River in the People's Republic of China, and covers a total area of about $628,000 \mathrm{~km}^{2}$ (Fig. 1). This region has a distinctive landscape where the main geomorphic landforms are "yuan" (cliff-edged plains), ridges, hills, and gullies of various sizes (Wang et al., 2011a). Most of the Loess Plateau is covered by loess deposits ranging from $30 \mathrm{~m}$ to $80 \mathrm{~m}$ in thickness; loess is a highly erosionprone soil that is susceptible to the forces of wind and water (Chen et al., 2008; Wang et al., 2010). The Loess Plateau generally has a subhumid and semi-arid climate, with extensive monsoonal influence

\footnotetext{
* Corresponding author at: State Key Laboratory of Earth Surface Processes and Resource Ecology, College of Global Change and Earth System Science, Beijing Normal University, Beijing 100875, PR China. Tel./fax: + 861058804191.

E-mail address: miaocy@vip.sina.com (C. Miao).
}

(Chen et al., 2014). The average annual precipitation ranges from $200 \mathrm{~mm}$ in the northwest to $750 \mathrm{~mm}$ in the southeast, and the rainy season (June-September) accounts for $60 \%$ to $70 \%$ of the total precipitation (Li et al., 2012; Gao et al., 2014). Rainfall is mainly from high-intensity storms (Wang et al., 2012). The combined effects of frequent heavy rainfall, steeply sloping landscapes, low vegetation cover, and highly erodible soils have made the Loess Plateau one of the most seriously eroded areas in the world, with an average annual soil loss of 2000 to $2500 \mathrm{t} / \mathrm{km}^{2}$ (Shi and Shao, 2000). The Loess Plateau is the main source of sediment in the Yellow River, and the amount of earth and sand flowing out from the Loess Plateau to the Yellow River can reach 1.6 billion tons/year (Wang et al., 2015). Soil loss from the Loess Plateau constitutes more than $90 \%$ of the total sediment entering the Yellow River (Chen et al., 2007).

With global warming, many regions have experienced changes in both the mean climate and climate extremes (Gao et al., 2013; Miao et al., 2013; Sun et al., 2014). A changing climate can lead to changes 


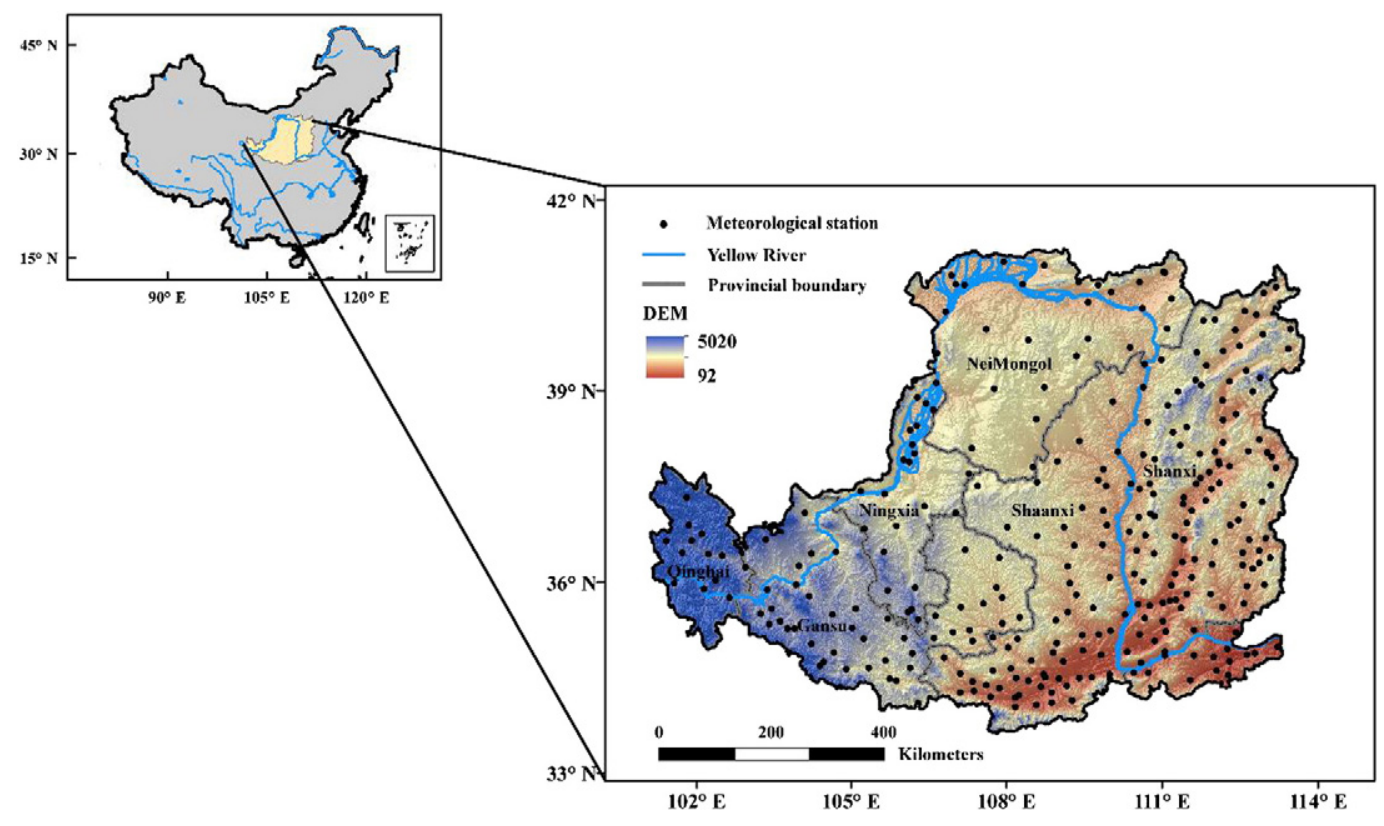

Fig. 1. Location of the Loess Plateau and the meteorological stations.

in the frequency, intensity, spatial extent, duration, and timing of extreme weather and climate events, and can result in unprecedented extreme climate events (IPCC, 2012). The Loess Plateau has a fragile ecological environment and is sensitive to climate change. Climate change can therefore affect soil erosion, water resources, and ecosystems on the Loess Plateau. For instance, changes in precipitation, especially in extreme precipitation events, would have an impact on soil erosion because most of the soil loss and environmental damage in this region is caused by infrequent but severe storms (Kang et al., 2001; Zhang and Liu, 2005; Li et al., 2011). In addition, growth of vegetation and crops is sensitive to changes in temperature and precipitation (Zhang and Nearing, 2005; Asseng et al., 2014). Previous studies have revealed that the observed decreases in runoff and sediment loss from the Loess Plateau to the Yellow River are partly due to a decrease in precipitation over the Loess Plateau (Wang et al., 2007; Miao et al., 2011; Kong et al., 2015). The planting boundary of some crops would move northward to higher latitudes and some plants may grow at higher altitudes owing to the climate warming (Li et al., 2013). The risk of crop diseases and pests would increase as a result of climate change (Piao et al., 2010). It is therefore urgent to analyze in detail how the climate on the Loess Plateau has changed in recent decades.

Several existing studies have examined the changes in temperature and precipitation on the Loess Plateau over recent decades. Several studies found that the region-averaged annual mean temperature on the Loess Plateau increased significantly over the last fifty years, whereas the region-averaged annual precipitation showed a non-significant negative trend (Bi et al., 2009; Wang et al., 2012). In terms of climate extremes, trends in the hot-day threshold (maximum temperature 90th percentile - the 10th hottest day per season), the cold-night threshold (minimum temperature 10th percentile - the 10th coldest night per season), and the longest heatwave (maximum number of consecutive days with maximum temperature $>$ long-term 90th percentile for each calendar day) have increased over the period 1961 to 2007, whereas the number of frost days has decreased (Li et al., 2010). Indices for extreme precipitation, such as the heavy rainfall threshold, the number of days with heavy rainfall, and the number of days with erosive rainfall (R12mm), were spatially distributed and decreased from the southeast to the northwest (Li et al., 2010; Wang et al., 2011a).

However, there are several factors that necessitate further analysis. First, these preexisting studies generally focused only on mean temperatures and precipitation or only on few indices for climate extremes.
Few studies have examined the changes in climate means and extremes synchronously over the Loess Plateau. Second, the previous studies mainly focused on changes in precipitation amount or frequency but ignored other features, such as intensity, duration, and type of precipitation. Moreover, questions remain as to whether changes in frequency or changes in intensity of rainfall contribute most to changes in the total precipitation amount. Third, owing to the distinctive climate on the Loess Plateau, with a well-defined rainy season and dry winters, the distribution of precipitation across the year tends to be very uneven. This temporal inequality in precipitation plays a significant role in the soil erosion, flow of water, and overall ecosystem on the Loess Plateau, but few studies have quantified it. Fourth, most previous studies focused only on the whole trends in precipitation and temperature, and dismissed the comparisons of dissimilar trends over the different periods. Taking more climate variables into consideration will be useful for determining the areas that are most sensitive to climate change. Furthermore, in previous studies, relatively few stations were used to study the climate on the Loess Plateau. Considering the complex topography and climate on the Loess Plateau, a dataset with dense meteorological data is needed to provide more accurate information about climate changes in this region.

Therefore, the objectives of this study are as follows: (1) to present an overview of the changes in mean and extreme climate over the Loess Plateau using gridded datasets with high-density data from meteorological stations; (2) to investigate the spatial patterns and temporal inequality in precipitation over the course of a year; and (3) to determine the dissimilarities in climate between past and recent decades.

\section{Data and methods}

\subsection{Data}

The observed daily precipitation (PR) datasets were taken from a gauge-based daily precipitation analysis on a $0.5^{\circ} \times 0.5^{\circ}$ grid (Shen et al., 2010). The daily mean temperatures (TM), maximum temperatures (TX), and minimum temperatures (TN) were obtained from a surface temperature $0.5^{\circ} \times 0.5^{\circ}$ gridded dataset (v2.0) developed by the National Meteorological Information Center of the China Meteorological Administration (National Meteorological Information Center, 2012). The datasets for precipitation and temperature were constructed from approximately 2400 station observations across China, including 
299 stations on the Loess Plateau (Fig. 1). Considering the consistency of temperature and precipitation over a long timeframe, we focused on the period between 1961 and 2011 in this study.

\subsection{Analysis methods}

\subsubsection{Climate indices}

Table 1 defines the twenty-five climate extreme indices recommended by the Expert Team on Climate Change Detection and Indices (ETCCDI) (Sillmann et al., 2013) that were used in this study. Among these, the first fourteen are indices for temperature extremes, and the remainder are indices for precipitation extremes. When focusing on mean-based measurements of precipitation, we analyzed only the precipitation amount, frequency, and intensity on wet days (daily $\mathrm{PR} \geq 1 \mathrm{~mm}$ ), corresponding to the indices chosen for precipitation extremes.

\subsubsection{Temporal inequality indices}

The Gini coefficient $(G)$ is the most commonly used measure to evaluate inequality of income or wealth in economics. Recently, the concept has been applied to other research fields, such as inequalities in global water use (Seekell et al., 2011) and plant size and fecundity (Damgaard and Weiner, 2000), and temporal inequalities in catchment discharge (Jawitz and Mitchell, 2011; Masaki et al., 2014). Rajah et al. (2014) used the Gini coefficient to analyze the distribution of precipitation and changes in precipitation. The Loess Plateau has a typical temperate continental monsoon climate with a well-defined rainy season (June-September) and a very dry winter. Rainfall is mainly from high intensity storms in the region (Wang et al., 2012). Therefore, in this paper, we applied the Gini coefficient to quantify the inequality in the annual temporal distribution of precipitation on the Loess Plateau.

To calculate the Gini coefficient for precipitation over the Loess Plateau, the all daily precipitation in a year at each grid location was sorted in ascending order and expressed as the series $P_{i}(i=1, \ldots, n ; n=365$ for normal years, $n=366$ for leap years). When a day has no rainfall, the corresponding $P_{i}$ was equal to 0 . Then the order series was summed

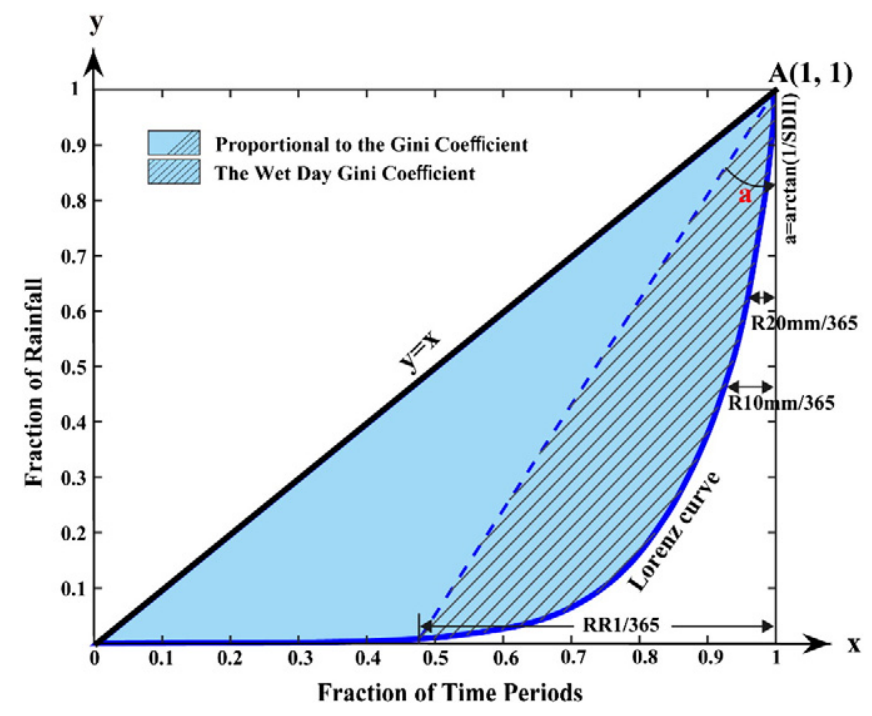

Fig. 2. Pictorial two-dimensional representation of the Lorenz curve and the Gini coefficient.

cumulatively, and converted to the proportion of total precipitation to obtain the Lorenz curve (the blue curve in Fig. 2). The Gini coefficient $(G)$ for precipitation is defined as double the area between the line of perfect equality $(y=x)$ and the Lorenz curve (the blue shaded region in Fig. 2), and can be estimated by the function described by Rajah et al. (2014):

$G=\frac{1}{n}\left(n+1-2\left(\frac{\sum_{i=1}^{n}(n+1-i) P_{i}}{\sum_{i=1}^{n} P_{i}}\right)\right)$.

The Gini coefficient ranges from 0 to 1 . The shape of Lorenz curve in Fig. 2 decides the values of Gini coefficient and shows the unevenly

Table 1

The indices for extreme temperature and precipitation indices used in this study.

\begin{tabular}{|c|c|c|c|}
\hline Label & Index name & Index definition & Units \\
\hline FD & Frost days & Number of days when $\mathrm{TN}<0{ }^{\circ} \mathrm{C}$ & days \\
\hline SU & Summer days & Number of days when $\mathrm{TX}>25^{\circ} \mathrm{C}$ & days \\
\hline ID & Ice days & Number of days when $\mathrm{TX}<0{ }^{\circ} \mathrm{C}$ & days \\
\hline TR & Tropical nights & Number of days when $\mathrm{TN}>20^{\circ} \mathrm{C}$ & days \\
\hline TN10p & Cold nights & Number of days when $\mathrm{TN}<10$ th percentile of the daily TN during the period 1961-1990 & days \\
\hline TX10p & Cold days & Number of days when TX $<10$ th percentile of the daily TX during the period $1961-1990$ & days \\
\hline TN90p & Warm nights & Number of days when TN $>$ 90th percentile of the daily TN during the period 1961-1990 & days \\
\hline TX90p & Warm days & Number of days when TX $>$ 90th percentile of the daily TX during the period 1961-1990 & days \\
\hline GSL & Growing season length & $\begin{array}{l}\text { Number of days between the first span of at least six consecutive days with } \mathrm{TM}>5{ }^{\circ} \mathrm{C} \text { and the first span after } 1 \text { st July } \\
\text { (Northern Hemisphere) of at least six consecutive days with } \mathrm{TM}<5{ }^{\circ} \mathrm{C}\end{array}$ & days \\
\hline TXx & Max TX & Maximum value of daily TX & ${ }^{\circ} \mathrm{C}$ \\
\hline TXn & Min TX & Minimum value of daily TX & ${ }^{\circ} \mathrm{C}$ \\
\hline $\mathrm{TNX}$ & Max TN & Maximum value of daily TN & ${ }^{\circ} \mathrm{C}$ \\
\hline TNn & Min TN & Minimum value of daily TN & ${ }^{\circ} \mathrm{C}$ \\
\hline DTR & Diurnal temperature range & The range between TN and TX & ${ }^{\circ} \mathrm{C}$ \\
\hline SDII & Simple daily intensity & The intensity on wet days (daily $P R \geq 1 \mathrm{~mm}$ ) & $\mathrm{mm}$ \\
\hline RX1day & Max 1-day precipitation & Maximum amount of precipitation on a single day & $\mathrm{mm}$ \\
\hline RX5day & Max 5-day precipitation & Maximum amount of precipitation measured over 5-day intervals & $\mathrm{mm}$ \\
\hline CDD & Consecutive dry days & Largest number of consecutive days with $\mathrm{PR}<1 \mathrm{~mm}$ & days \\
\hline CWD & Consecutive wet days & Largest number of consecutive days with $\mathrm{PR}>=1 \mathrm{~mm}$ & days \\
\hline R95p & Very wet days & Number of days when PR $>$ 95th percentile of precipitation on wet days during the period 1961-1990 & days \\
\hline R99p & Extremely wet days & Number of days when PR > 99th percentile of precipitation on wet days during the 1961-1990 period & days \\
\hline R95pTOT & $\begin{array}{l}\text { Precipitation fraction due to very } \\
\text { wet days }\end{array}$ & Percentage of total precipitation from very wet days & $\%$ \\
\hline R99pTOT & $\begin{array}{l}\text { Precipitation fraction due to } \\
\text { extremely wet days }\end{array}$ & Percentage of total precipitation from extremely wet days & $\%$ \\
\hline $\mathrm{R} 10 \mathrm{~mm}$ & Heavy precipitation days & Number of days with PR $>10 \mathrm{~mm}$ & days \\
\hline $\mathrm{R} 20 \mathrm{~mm}$ & Very heavy precipitation days & Number of days with PR $>20 \mathrm{~mm}$ & days \\
\hline
\end{tabular}


temporal distribution of precipitation in a year. $G=0$ represents a uniform distribution of precipitation throughout the year and occurs when the Lorenz curve and the line $y=x$ in Fig. 2 overlap. $G=1$ indicates that the entire annual precipitation occurred on a single day and there was no precipitation during the rest of the year, the corresponding Lorenz curve would be overlapped with the line 0-1-A formed by the $x$ axis and $y$ axis in Fig. 2. Moreover, compared with the single precipitation indices, Fig. 2 can indicate the knowledge of precipitation characters in more than one aspect. The precipitation indices, such as RR1, R10mm. R20mm, and SDII, can be displayed visually by Fig. 2 at the same time. It is obvious that the Gini coefficient is closely linked to the frequency and intensity of precipitation in a year. Thus, we also used the wet-day Gini coefficient defined by Rajah et al. (2014) to measure how unevenly rainfall is spread across only the wet days (precipitation $>1 \mathrm{~mm}$ ) during the year. The wet-day Gini coefficient is defined as the area between the dashed blue line and the Lorenz curve (the slash shadow region) in Fig. 2.

\subsubsection{Trend detection}

The statistical significance of the trends in the temperature and precipitation indices at each grid point on the Loess Plateau was tested using the nonparametric Mann-Kendall test (Mann, 1945), and the trend magnitudes were computed using Sen's slope estimator (Sen, 1968).

\subsubsection{The standardized Euclidean distance (SED)}

In this study, we aimed to comprehensively evaluate the sensitivity of different regions of the Loess Plateau to climate change over the past fifty years. We therefore applied the standardized Euclidean distance (SED) approach (Williams et al., 2007) to quantify dissimilarities in climate between the 1960s and the 2000s across the plateau. The standardized Euclidean distance (SED) at grid point $i$ was calculated as follows:

$S E D_{i}=\sqrt{\sum_{k=1}^{K} \frac{\left(b_{k}-a_{k}\right)^{2}}{s_{k}^{2}}}$

where, the $i$ is the grid point $i . S E D_{i}$ indicates the standardized Euclidean distance (SED) at grid point $i$. The $a_{k}$ and $b_{k}$ are the means for the climate variable $k(k=1, \ldots, K)$ in the 1960s and the 2000s, respectively, at corresponding grid points. $s_{k}$ is the standard deviation of the interannual variability between 1961 and 1970. Generally, higher SED values represent greater changes in climate, and vice versa. Firstly, for temperature, three temperature variables are used, including TM, TX, and TN to obtain the value of SED. Secondly, when quantifying the dissimilarities between the 1960s and the 2000s in precipitation, the RR1, SDII, R20mm, and R10mm were involved to calculate the SED. Thirdly, to estimate the overall change in climate between the 1960s and the 2000s, both temperature and precipitation variables (including TM, TX, TN, RR1, SDII, R20mm, and $\mathrm{R} 10 \mathrm{~mm}$ ) were taken into consideration.

\section{Results}

\subsection{Temperature change on the Loess Plateau between 1961 and 2011}

\subsubsection{Mean-based temperature changes}

The climatology of the mean (TM), maximum (TX), and minimum (TN) temperatures over the Loess Plateau is shown in Fig. 3(a, b, and c). The Loess Plateau displays consistent spatial characteristics for these variables, with the values gradually decreasing from the southeast to the northwest of Loess Plateau. The southwest region is at higher altitude, so temperatures there are slightly lower. The annual TM ranged from -10 to $15{ }^{\circ} \mathrm{C}$. The $\mathrm{TX}$ values were above $0{ }^{\circ} \mathrm{C}$ in all regions. TN values were below $5{ }^{\circ} \mathrm{C}$ except in the southeast region.

The monotonic trends in annual TM, TX, and TN over the Loess Plateau between 1961 and 2011 are shown in Fig. 3(d, e, and f). Statistically significant positive trends $(p<0.05)$ were identified in all three variables over almost all regions during the past half century, whereas decreasing trends were found in only a handful of grid locations in the south of the plateau. However, the rates of change and the spatial features of these trends were not consistent across the three variables. It can be seen in Fig. 3 that the upward trend was stronger for TN than for TM or TX, except in some grid locations in the southeast of the plateau. The warming in TN in the southeast was generally weaker than in the northwest; grid locations with increasing trends of approximately $0.08{ }^{\circ} \mathrm{C} / \mathrm{yr}$ were observed in the northwest part of the plateau. In contrast, rates of change in TX were relatively homogeneous across the plateau, with values around $0.02-0.04{ }^{\circ} \mathrm{C} / \mathrm{yr}$. It is worth noting (a) Mean temperature

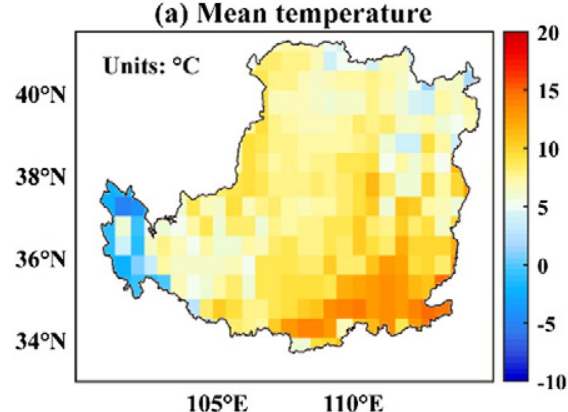

(d) Trends in mean temperature

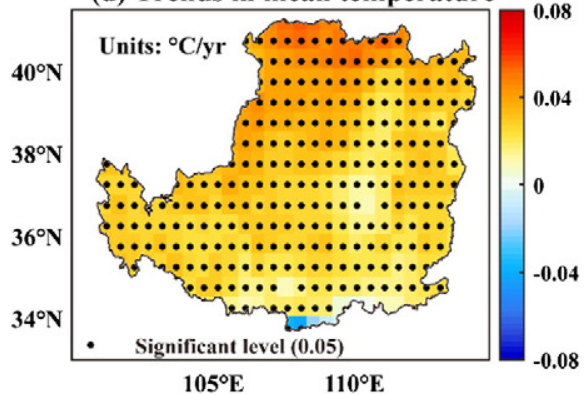

(b) Maximun temperature

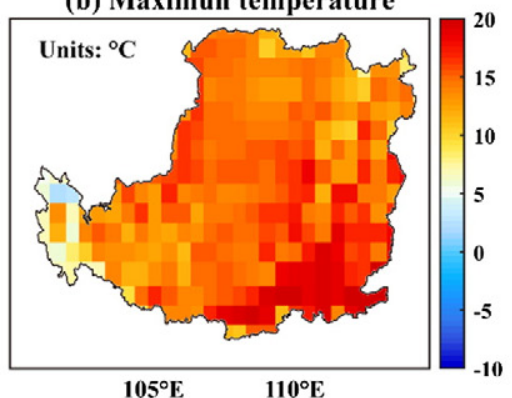

(e) Trends in maximun temperature

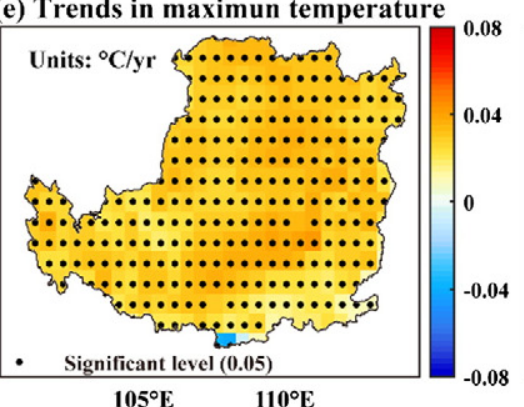

(c) Minimun temperature

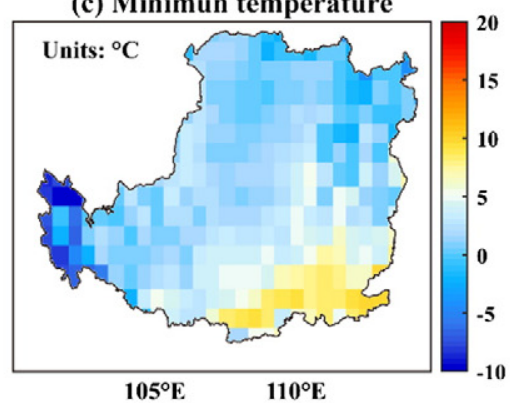

(f) Trends in minimun temperature

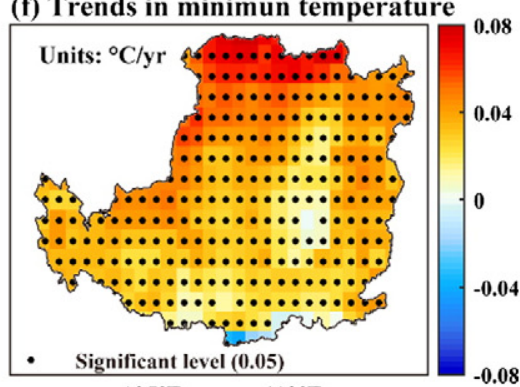

Fig. 3. The climatology (a, b, c) and observed trends (d, e, f) in the mean, maximum, and minimum temperatures between 1961 and 2011. 
that the grid locations in the southeast of the Loess Plateau showed slightly greater warming trends in TX but had minimal changes in TN. Despite these inconsistencies between trends in TX and TN, the spatial patterns of trends for TM closely approximate the changes in TN. The rates of change in TM were approximately $0.04-0.06{ }^{\circ} \mathrm{C} / \mathrm{yr}$.

\subsubsection{Changes in extreme temperature events}

Fig. 4 plots the spatial patterns of trends in the indices for temperature extremes during the period 1961 to 2011. Consistent with the warming in TX and TN, the number of tropical nights (TR) and summer days (SD) had upward trends and the number of frost days (FD) and ice days (ID) had downward trends. The changes in these four indices were greater in the northwest region than in the southeast, resulting in statistically significant changes occurring mainly in the northwest region of the Loess Plateau. The rate of change is weaker for TR than for the other indices. We observed a consistent spatial pattern in the evolution of the TN-based percentile indices, similar to the pattern for TN. Decreasing and increasing trends were found for cold nights (TN10p) and warm nights (TN90p), respectively. The absolute rate of change appeared to be weaker for TN10p than TN90p. For the TX-based percentile indices, the trends for cold days (TX10p) and warm days (TX90p) were similar to those for TN10p and TN90p, respectively, but were less pronounced. The rate of change for TN90p was often greater than $1 \% / \mathrm{yr}$, whereas the rate of change for TX90p was generally less than $1 \% / \mathrm{yr}$. A similar result was observed for TN10p and TX10p. Compared with the spatial patterns for TN10p and TN90p, TX10p and TX90p showed greater rates of change in the eastern and southwest regions. Furthermore,
TX10p had fewer grid locations with significant changes than the other percentile indices. The absolute indices TXx (the maximum TX) and TNx (the maximum TN) also showed positive trends over the past fifty years, particular in the northwest and southwest regions. The area with significant positive trends was larger and more pronounced for TNx than for TXx. Mildly decreasing trends were observed in the center of the plateau for the TXn and TNn; however the decrease was only approximately $0.02^{\circ} \mathrm{C} / \mathrm{yr}$ and was not statistically significant. Overall, the changes in TXn and TNn were less obvious than the changes in TXX and TNX, and in most regions the trends were not significant. The few grid locations with significant trends were scattered toward the edges of the plateau (especially for TNn).

As a consequence of this warming of the climate over the Loess Plateau, the growing season length (GSL) in the area also showed an upward trend over the past fifty years. This was particularly true for the western and northern regions where the length of growing season increased at a rate of more than 0.5 days/yr, which is significant at the $p<0.05$ level. The increasing GSL may provide opportunities for earlier planting, ensuring maturation and possibilities for multiple cropping (depending on water availability) (Linderholm, 2006). The diurnal temperature range (DTR) is another climate index that has several important applications to agriculture. The DTR decreased over the period 1961 to 2011 across large areas of the plateau, especially in the northwest region. This result follows from the fact that minimum temperatures showed a larger increase than maximum temperatures. A few grid locations with increasing DTR trends were scattered in the southeast region, which was associated with more severe changes in TX than TN.
FD

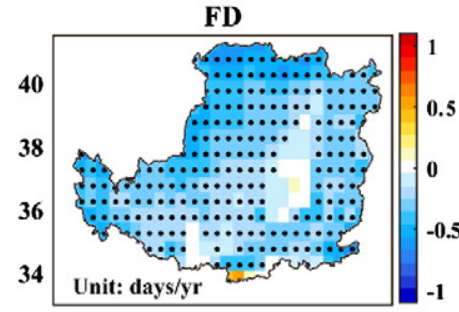

TN10p

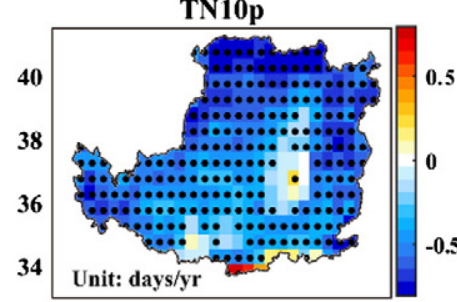

TXx

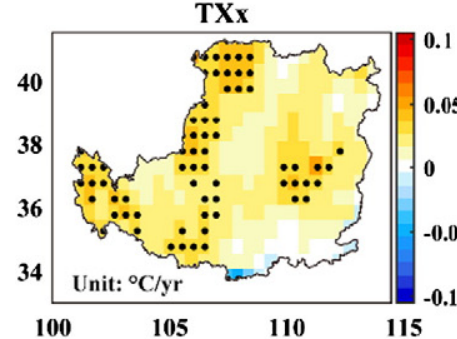

SD

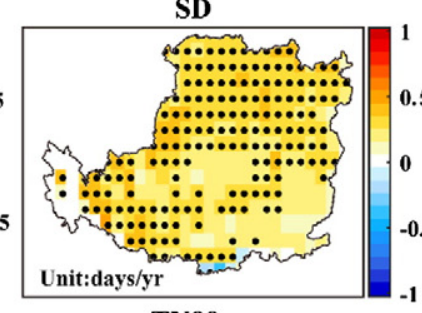

TN90p

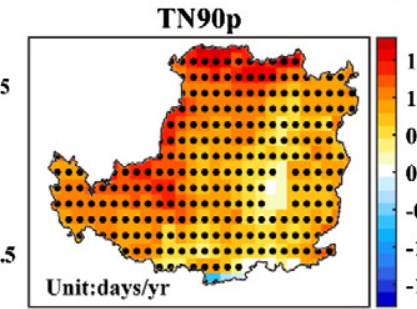

TR

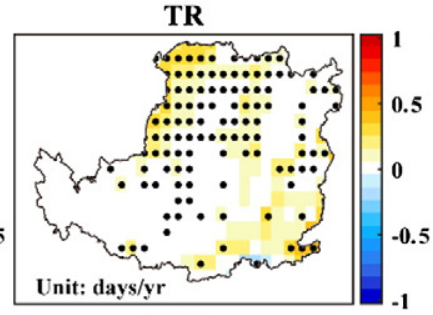

TX10p
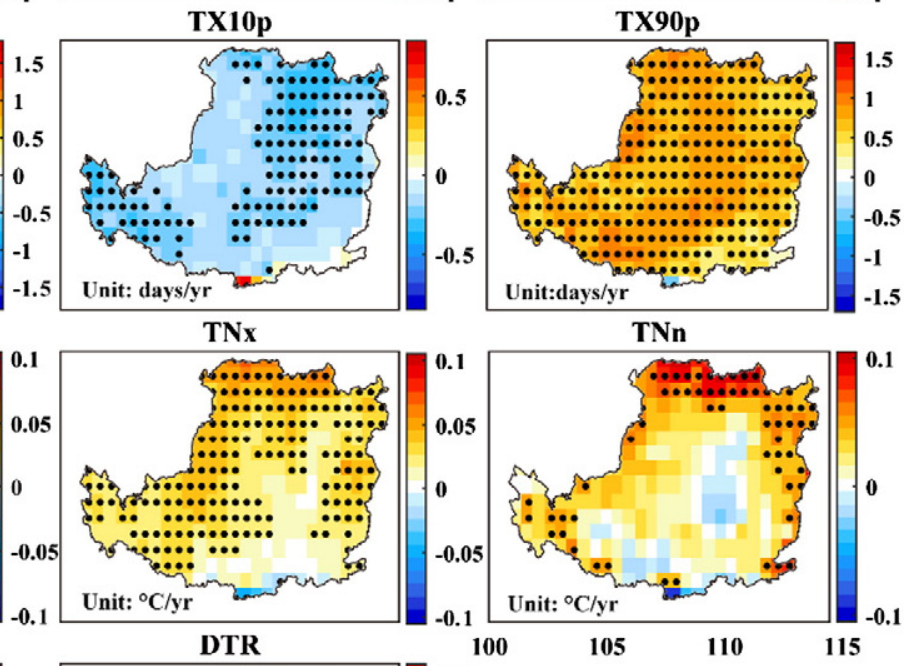

ID

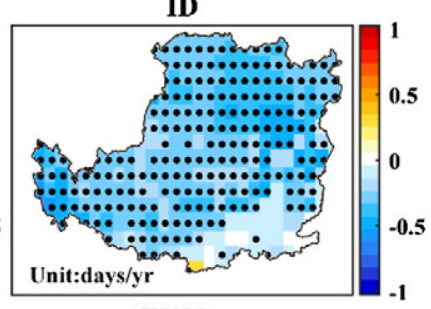

TX90p

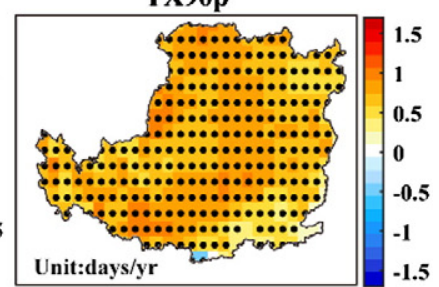
.5

15
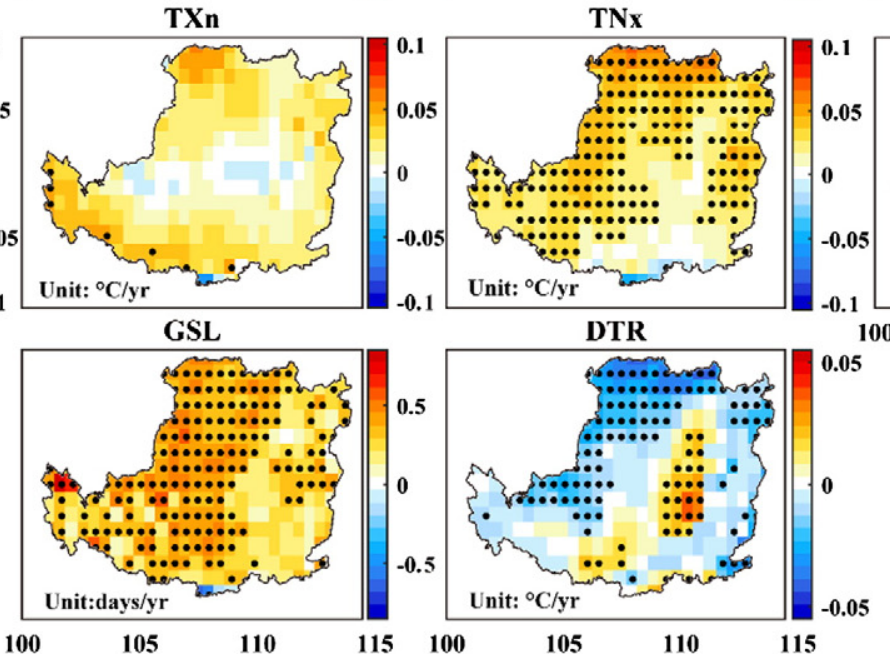

Fig. 4. Change trends in extreme temperature events during the period 1961 to 2011. 
Table 2

Trends in the indices for temperature extremes (values in bold and with an asterisk were statistically significant at the $p<0.05$ level).

\begin{tabular}{|c|c|c|c|c|c|c|c|c|}
\hline Index & Unit & Trend & Index & Unit & Trend & Index & Unit & Trend \\
\hline TXx & ${ }^{\circ} \mathrm{C} / \mathrm{yr}$ & 0.014 & TNx & ${ }^{\circ} \mathrm{C} / \mathrm{yr}$ & 0.015 & FD & days/yr & $-0.250^{*}$ \\
\hline TXn & ${ }^{\circ} \mathrm{C} / \mathrm{yr}$ & 0.006 & TNn & ${ }^{\circ} \mathrm{C} / \mathrm{yr}$ & 0.019 & SD & days/yr & $0.250^{*}$ \\
\hline TX90p & $\% / \mathrm{yr}$ & $0.800^{*}$ & TN90p & $\% / y r$ & $1.146^{*}$ & ID & days/yr & $-0.324^{*}$ \\
\hline TX10p & $\% / \mathrm{yr}$ & -0.226 & TN10p & $\% / \mathrm{yr}$ & $-0.619 *$ & TR & days/yr & 0 \\
\hline GSL & days/yr & $0.2791^{*}$ & DTR & ${ }^{\circ} \mathrm{C} / \mathrm{yr}$ & -0.007 & & & \\
\hline
\end{tabular}

The regional average trends across the entire Loess Plateau for the extreme temperature indices are shown in Table 2. Many of these indices-FD, SD, ID, TX90p, TN90p, and TN10p-showed statistically significant changes between 1961 and 2011. The other indices showed nonsignificant changes. Slight upward trends were observed for TXX, TXn, TNx and TNn, whereas a decreasing trend was observed in DTR.

\subsection{Precipitation change on the Loess Plateau between 1961 and 2011}

\subsubsection{Changes in the amount, frequency, and intensity of precipitation on} wet days

In this study, we focused only on wet days (when precipitation $\geq 1 \mathrm{~mm}$ ), therefore the terms "amount", "frequency", and "intensity" refer specifically to precipitation falling on wet days. Fig. 5 displays the climatology of the total annual amount of precipitation ( $\mathrm{mm}$ ), the simple daily intensity index (SDII, $\mathrm{mm} /$ day), and the frequency (RR1, days) of wet days on the Loess Plateau (a, b, and c). The SDII is defined as the total annual precipitation divided by the number of wet days. In general, the annual amount of precipitation, SDII, and RR1 all gradually decreased from the southeast to the northwest of the plateau. However, the frequency of wet days (RR1) was higher in the mountainous southwest region than in other regions, with values above 80 days, although the daily intensity (SDII) in this region was relatively weak. Therefore, in the southwest region, the total amount of precipitation on wet days was higher than in the northwest region but lower than in the southeast region.

Fig. 5(d, e, f) shows the spatial trends for the rates of change in the same variables over the past fifty years. The annual amount of precipitation decreased over large areas of the Loess Plateau, particularly in the southeast region. The grid locations where these decreasing trends were statistically significant were concentrated in the southern regions. Over the entire plateau, there were only a few grid locations with upwards trends, all nonsignificant and scattered across the southwest and northern regions. The basic spatial pattern for RR1 rates of change is similar to that described above for the annual amount of precipitation. Downward rates with values of about -0.1 days/yr were observed in most grid locations over the southern region of the Loess Plateau, and some grid locations had significant decreases of more than -0.3 days/yr. However, the locations with maximum change in RR1 did not entirely overlap with the locations with maximum change in precipitation amount. This was because of discrepancies in the patterns and rates for precipitation frequency and intensity. For instance, the grid locations with the most pronounced downward trends in RR1 did not show significant downward changes in the annual precipitation amount because of the weak decrease or even slight increase in precipitation intensity. In contrast to the general decline in precipitation amount and RR1, the SDII had slightly increasing trends across approximately half of the plateau, although values were below $0.03 \mathrm{~mm} / \mathrm{yr}$.

Because the change in the total amount of precipitation on wet days results from changes in both frequency and intensity, it is necessary to pinpoint the relationship between these variables. In this study, we formed four categories based on the sign (positive or negative) of the trends in precipitation frequency and intensity, and mapped these onto the spatial map of changes in wet-day precipitation amount (Fig. 6). Across the Loess Plateau, 15.12\% (39/258) of the total grid locations had increases in the wet-day precipitation amount. There are only (a) Precipitation amount

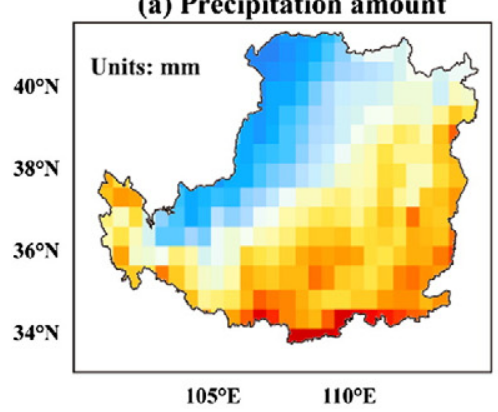

(d) Trends in precipitation amount

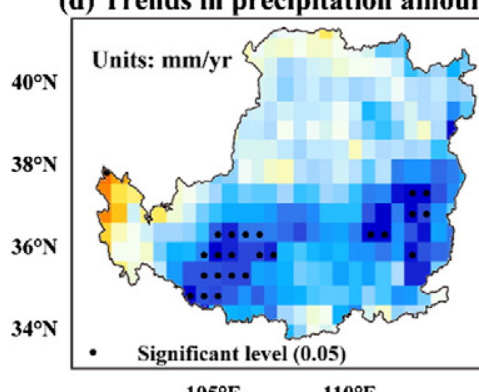

(b) SDII
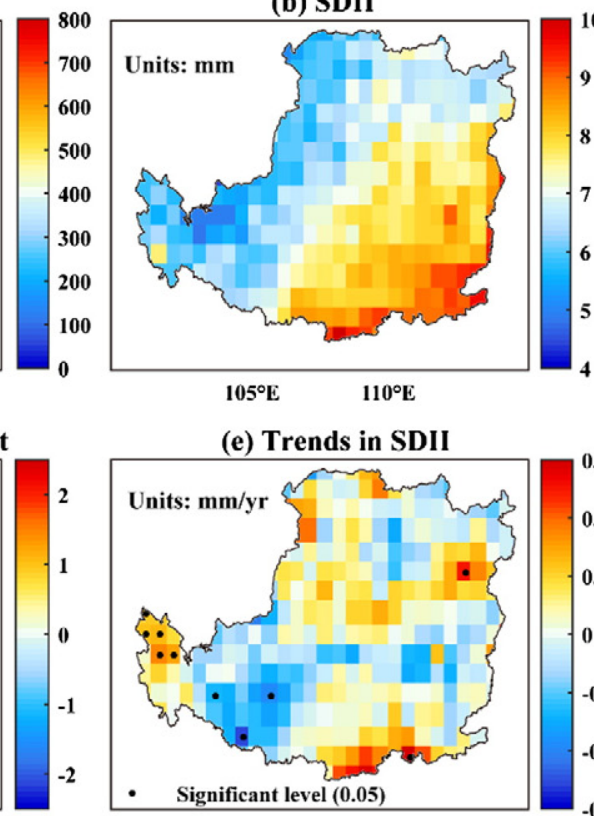

(e) Trends in SDII

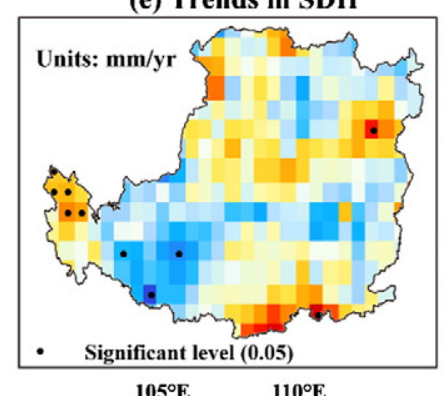

(c) RR1

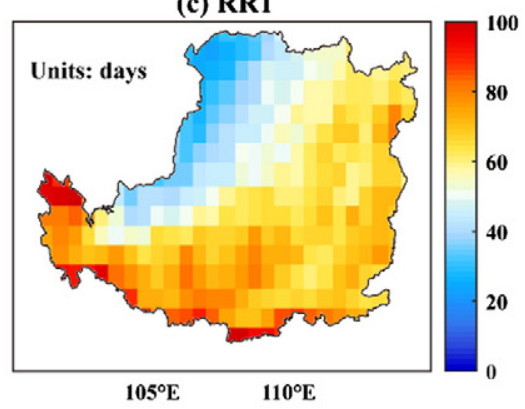

(f) Trends in RR1
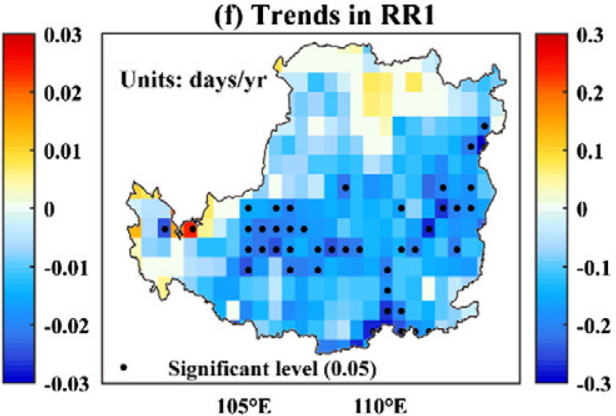

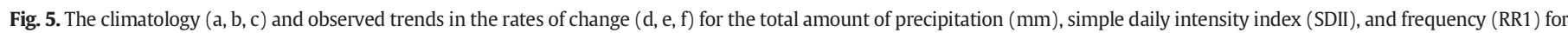
wet days between 1961 and 2011 . 


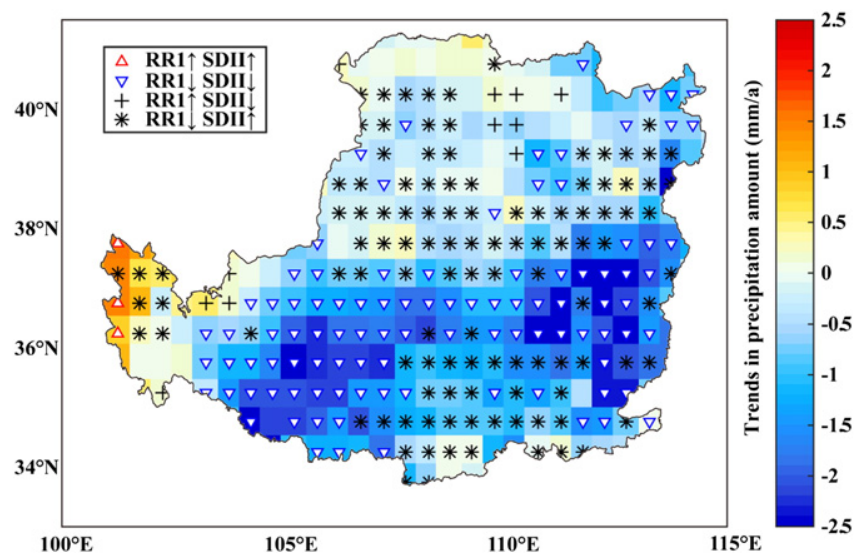

Fig. 6. Summary of estimated changes between 1961 and 2011 in the frequency of wet days (RR1) and the intensity of precipitation on wet days (SDII), superimposed on the spatial map of changes in total wet-day precipitation.

3 grid locations where the increase in amount was due to increases in both frequency and intensity. In 16 grid locations, the increased precipitation amount was mainly caused by an increase in SDII. Only $2.71 \%$ (7/258) of the total grid locations showed an increase in both amount and frequency but a decrease in intensity. Most grid locations over the plateau (219/258; 84.88\%) showed drying trends. Approximately two fifths $(97 / 258)$ of grid locations with drying trends were the result of decreases in both intensity and frequency of precipitation. These grid locations were mainly located in the center and south of the plateau. However, approximately half $(96 / 258)$ of the locations with drying trends were the result of decreases in the frequency of wet days, despite increases in precipitation intensity. Grid locations falling into this category occurred mainly in the southeast and the north of the plateau. There were only 4 grid locations where the decrease in precipitation amount was caused by a decrease in intensity that outweighed an increase in frequency.

\subsubsection{Temporal inequalities in precipitation}

The Gini coefficient indicates how evenly rainfall is distributed over the course of a year. Fig. 7a shows the spatial pattern of the Gini coefficient across the Loess Plateau. Because of the distinctive climatological characteristics of the region, the Loess Plateau tends to have large Gini coefficients ranging from 0.8 to 0.95 , indicating that the temporal distribution of precipitation is very uneven. The distribution of the Gini coefficient gradually increased from the southeast to the northwest region, which is the opposite pattern to the distribution for precipitation amount. The results indicate that, in the drier region, the temporal distribution of precipitation was more uneven over the course of the year. Increasing and decreasing trends in the Gini coefficient were identified in $88.76 \%$ and $11.24 \%$ of grid locations, respectively (Fig. $7 \mathrm{~b}$ ). Increasing trends were found mainly in the southern and northwest regions. About a quarter of the grid locations with increasing trends had a statistically significant change $(p<0.05)$. Decreasing trends in the Gini coefficient were found in the center of the northern region and in a few scattered grid locations distributed in the southwest region. Over the past fifty years, the temporal inequality in precipitation over the wettest region of the Loess Plateau has been extensively enhanced. In a small part of the semi-arid region the temporal inequality was slightly reduced, but this effect was not statistically significant.

The Gini coefficient is highly sensitive to the number of wet days in a given year, so we also calculated the wet-day Gini coefficient, which
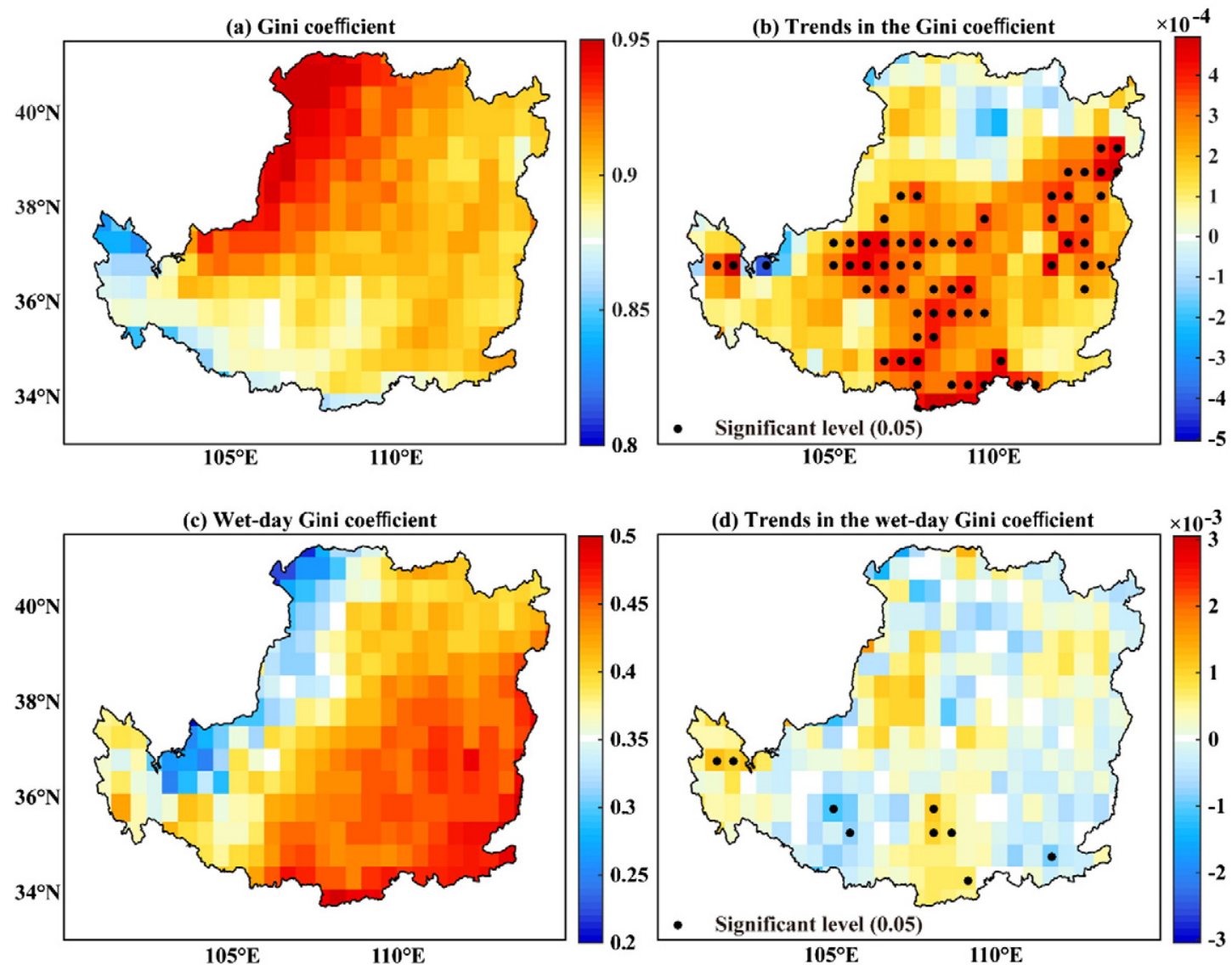

(d) Trends in the wet-day Gini coefficient

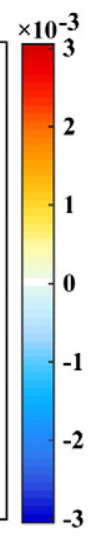

Fig. 7. Estimated change in the Gini coefficient and the wet-day Gini coefficient between 1961 and 2011. 
provides a measure of how evenly the rainfall is distributed across wet days ( $P R \geq 1 \mathrm{~mm}$ ). Fig. 7c presents the spatial distribution of wet-day Gini coefficients, based on annual average values. The spatial pattern for the wet-day Gini coefficient was similar to the pattern for precipitation amount on wet days, but opposite to the pattern for the Gini coefficient. The values for the wet-day Gini coefficient were generally greater than 0.4 in the southeast region, but lower than 0.3 in the western region. During the period between 1961 and 2011, values for the wet-day Gini coefficient stayed approximately constant, as shown in Fig. $7 \mathrm{~d}$. The central southern region, the southwest region, and parts of the central western region showed slight increases, indicating a mild increase in light and extreme events at the expense of dry and moderate events. Declining trends in the wet-day Gini coefficient were observed in about $45 \%$ of all grid locations, indicating that the distribution of precipitation on wet days became more uniform in those locations in the past fifty years.

\subsubsection{Changes in extreme precipitation events}

Fig. 8 shows the rates of change in extreme precipitation indices across the Loess Plateau between 1961 and 2011. It is obvious from the figure that the very wet days (R95p) decreased in the southern regions, with a rate of change of approximately -0.1 days/yr. Significant increases were observed in a few grid locations in the southwest region. For extremely wet days (R99p), large areas of the plateau did not show any changes and only a few grid locations showed significant changes. Nevertheless, the percentage of precipitation falling on extremely wet days (R99pTOT) showed fixed trends over the region, with rates of change varying from $-0.2 \% / \mathrm{yr}$ to $0.2 \% / \mathrm{yr}$. The combined changes in R99p and R99pTOT indicate that the extremely wet days contribute less on the decreasing precipitation over the fifty-year period.

A decreasing trend was identified for RX5day in large area over the Loess Plateau, with values around $-0.2 \mathrm{~mm} / \mathrm{yr}$. In the center of the southern region, significant upward trends were observed for RX1day but no significant upward changes were seen for RX5day. Over the entire plateau, there was a general downward trend for both these indices, particularly in the southeast region. Rates of change were slightly larger for RX5day than for RX1day, in most grid locations.

For the duration indices, Fig. 8 shows that the southeast and northwest regions experienced more consecutive dry days (CDD) recently, indicating a greater risk of drought. The increase in the northwest region $(<0.4$ days/yr) was weaker than the increase in the southeast region ( $>0.4$ days/yr). However, there was a general decrease in CDD in the southwest region. In contrast to the changes in $\mathrm{CDD}$, the number of consecutive wet days (CWD) did not change much, with only a few grid locations scattered in the eastern and southwest regions showing decreasing and increasing trends, respectively. The spatial patterns for the change in the number of heavy precipitation days (R10mm) and very heavy precipitation days (R20mm) were similar to the patterns for R90p and R99p, respectively. In the southern region, R10mm declined at a rate of more than -0.05 days/yr. Consistent with the pattern for R99p, values for R20mm did not change much over the past fifty years. Overall, the changes in precipitation indices were general weaker than the changes in temperature indices; there were fewer changes that were statistically significant at the $p<0.05$ level.

The regional average trends for the precipitation indices across the Loess Plateau are shown in Table 3. The CDD and RX5day indices showed positive trends between 1961 and 2011. The Rx1day, R99pTOT, R95p, and R95pTOT indices all showed slightly negative trends. However, none of the changes were significant.

\subsection{Sensitivity of climate change}

To comprehensively evaluate the combined changes in temperature and precipitation on the Loess Plateau over the past fifty years, we applied the standardized Euclidean distance (SED) approach. This allowed us to quantify the dissimilarities in climate between the 1960s and the 2000s. Fig. 9a shows the combined changes in terms of the temperature variables (TM, TX, and TN). Overall, the most remarkable dissimilarities between past (1960s) and recent (2000s) temperatures occurred in the northern and southwest regions (SED values $>4$ ). The change in temperature in the southeast and center regions was relatively weak. For
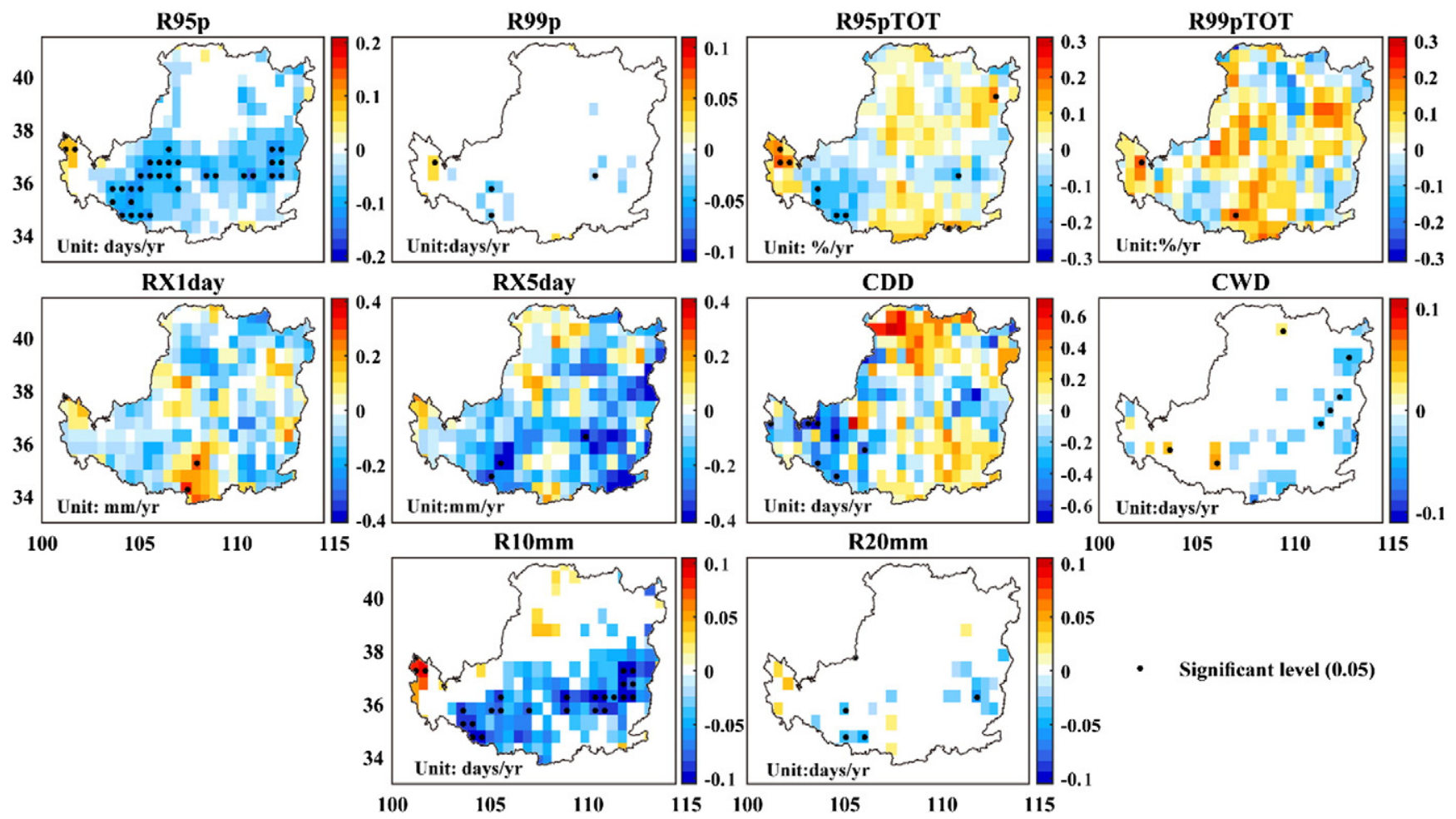

- $\quad$ Significant level (0.05)

Fig. 8. Change trends in extreme precipitation events during the period 1961 to 2011. 
Table 3

Trends in the precipitation indices (values in bold and with an asterisk were statistically significant at the $p<0.05$ level).

\begin{tabular}{|c|c|c|c|c|c|c|c|c|}
\hline Index & Unit & Trend & Index & Unit & Trend & Index & Unit & Trend \\
\hline $\mathrm{CDD}$ & days/yr & 0.377 & R99p & $\mathrm{mm} / \mathrm{yr}$ & 0 & $\mathrm{R} 10 \mathrm{~mm}$ & days/yr & 0 \\
\hline CWD & days/yr & 0 & R95p & $\mathrm{mm} / \mathrm{yr}$ & -0.064 & $\mathrm{R} 20 \mathrm{~mm}$ & days/yr & 0 \\
\hline Rx1day & $\mathrm{mm} / \mathrm{yr}$ & -0.011 & R99pTOT & $\% / y r$ & -0.032 & R95pTOT & $\% / \mathrm{yr}$ & -0.032 \\
\hline Rx5day & $\mathrm{mm} / \mathrm{yr}$ & 0.002 & SDII & $\mathrm{mm} / \mathrm{yr}$ & 0.007 & & & \\
\hline
\end{tabular}

the precipitation variables (RR1, SDII, R20mm, and R10mm), the changes were slightly larger in the southwest region and part of the southeast region than in other regions. However, it is obvious that the change in precipitation was much weaker than the change in temperature. Fig. 9c shows the change in climate between the 1960s and the 2000s when both temperature and precipitation variables were taken into consideration. Across the entire plateau, the largest changes in climate were found in the southwest region. This region is at greater sensitivity for climate change than the other regions.

\section{Discussion and conclusions}

We used gridded data from 299 weather stations on the Loess Plateau to comprehensively and synchronously analyze changes in mean and extreme temperature and precipitation variables between 1961 and 2011. For the temperature variables, we identified statistically significant positive trends $(p=0.05)$ in TM, TX, and TN between 1961 and 2011 over almost all regions of the plateau. Rates of change for TM and TN showed similar spatial patterns, with the warming in the southeast region being generally weaker than the warming in the northwest region; however, for TX, severe warming was observed in the southeast. The increase in TN was larger than the increase in TX across the plateau as a whole, which is consistent both with global trends (Braganza, 2004; Lewis and Karoly, 2013) and with other regional trends (Shen et al., 2014; Wang et al., 2014). The inconsistent rates of change between TX and TN result in a general decrease in DTR, which is highly sensitive to small changes in either TX or TN (Dai et al., 1999). However, there were a few grid locations scattered across the northwestern part of the southeast region of the plateau that had increased trends in DTR. These increases in DTR may have been partly due to the significant decrease in wet days observed in that subregion (Fig. 5f). Overall, the rate of increase in warm days and warm nights exceeded the rate of decrease in cold nights and cold days, indicating that the greatest changes occurred in the high percentile values for both TX and TN.

In addition, this recent warming in the climate has resulted in an increase in the length of the growing season. Linderholm (2006) have suggested that an increased growing season length may provide opportunities for earlier planting, ensuring crop maturation and the possibility of multiple cropping. However, persistent increases in the length of the growing season may lead to long-term increases in carbon storage and changes in vegetation cover, which may in turn further affect the climate system.
The total amount of precipitation on wet days decreased over large areas of the plateau between 1961 and 2011, particularly in the southeast region: the grid locations with statistically significant downward trends were mainly concentrated in the south. Many previous studies have shown that the decrease in precipitation over the southeast region may be related to changes in the East Asian summer monsoon. This monsoon has been relatively weak since the 1970s and, because the southeast half of the Loess Plateau is located in the fringe zone for the monsoon, it largely controls precipitation in that region of the plateau (Qian et al., 2007; Zhou et al., 2010; Wang et al., 2012).

The changes in the total amount of precipitation on wet days are the results of changes in both the frequency of wet days and the intensity of precipitation on the wet days. Therefore, we assessed changes in the amount, frequency, and intensity of precipitation concurrently in this study. We showed that, in approximately half of the grid locations with drying trends (96 locations), the decrease in precipitation was the result of a decrease in the frequency of wet days despite a concomitant increase in rainfall intensity. In approximately $37.60 \%$ of the total area with drying trends, the decrease in precipitation was caused by decreases in both the frequency and intensity of rainfall.

Precipitation over the Loess Plateau is seasonal in nature. We calculated the Gini coefficients and the wet-day Gini coefficients for the period 1961 to 2011 to quantify the annual temporal inequality in precipitation. Overall, the drier region concentrated on the northwest of the Loess Plateau showed larger uneven temporal distribution of precipitation with the higher values Gini coefficients. The smaller wet-day Gini coefficient in this subregion indicated that there were small number wet days and annual precipitation was mainly from few intense precipitation. The significant increase in the Gini coefficient in the southeast region indicates that temporal inequalities in precipitation in the wet region had increased over the past fifty years. However, tiny and non-significant trends in the wet-day Gini coefficient but the significant increase in the Gini coefficient in some grids were likely related to fact that the number of days with light $(1 \mathrm{~mm} \leqq P R \leq 10 \mathrm{~mm})$ and moderate (10 $\mathrm{mm} \leqq \mathrm{PR} \leq 20 \mathrm{~mm}$ ) precipitation decreased. In the center of southern and the southwest of the Loess Plateau, the combined increasing trends in wet-day Gini coefficient and decrease trends in wet-days (Fig. 5f) indicated slight increase in precipitation fraction due to extreme events. The increase in the R95pTOT and R99pTOT in this region (Fig. 8) could confirm this point to some extent. Overall, there were only minor changes in extreme precipitation over the Loess Plateau. There were only weak changes in R99p, R99pTOT, and R20mm over the Loess Plateau.
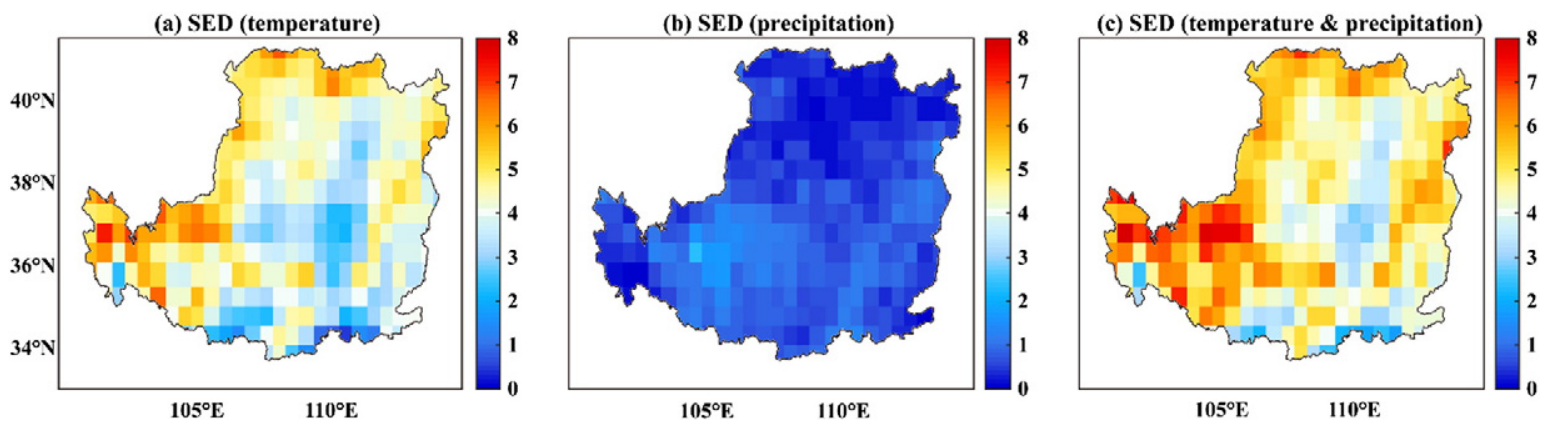

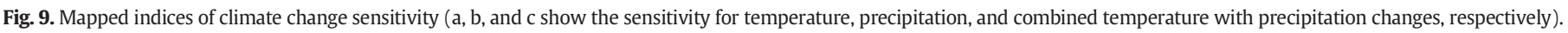


We have observed a change in the climate over the Loess Plateau, consistent with the context of global warming. Taking changes in both temperature and precipitation into consideration, the region with the most notable climate change was observed to be the southwest region. The Loess Plateau has the most serious soil erosion in China and is the main source of sediment in the Yellow River. The plateau is also sensitive to climate change and has a fragile ecological environment. If the current climate change continues, the Loess Plateau will suffer more challenges and damage. Increasing temperatures will intensify evaporation and decreasing precipitation will reduce the amount of surface water, which will reduce water availability and result in more droughts. Vegetation and crops will face more severe damage. Importantly, although we observed a reduction in precipitation, there was little change in the measures of extreme precipitation events. Consequently, despite the overall reduction in rainfall, there will be no reduction in floods or soil erosion over the Loess Plateau. Thus, the Loess Plateau will face more challenges in the future. The impact of further potential climate change should be explored in future studies.

\section{Acknowledgments}

Funding for this research was provided by the major program of the National Natural Science Foundation of China (no. 41390464), the National Natural Science Foundation of China (no. 41440003), and State Key Laboratory of Earth Surface Processes and Resource Ecology (2013-ZY-12). We are grateful to the products' developers for providing the gridded climate data sets.

\section{References}

Asseng, S., Ewert, F., Martre, P., et al., 2014. Rising temperatures reduce global wheat production. Nat. Clim. Chang. 5, 143-147.

Bi, H.X., Liu, B., Wu, J., et al., 2009. Effects of precipitation and landuse on runoff during the past 50 years in a typical watershed in the Loess Plateau, China. Int. J. Sediment Res. $24,352-364$

Braganza, K., 2004. Diurnal temperature range as an index of global climate change during the twentieth century. Geophys. Res. Lett. 31, L13217. http://dx.doi.org/10.1029/ 2004 GL019998.

Chen, L.D., Wei, W., Fu, B.J., Lu, Y.H., 2007. Soil and water conservation on the Loess Plateau in China: review and perspective. Prog. Phys. Geogr. 31, 389-403.

Chen, H.S., Shao, M.G., Li, Y.Y., 2008. The characteristics of soil water cycle and water balance on steep grassland under natural and simulated rainfall conditions in the Loess Plateau of China. J. Hydrol. 360, 242-251.

Chen, F., Yuan, Y., Zhang, R., Qin, L., 2014. A tree-ring based drought reconstruction (AD 1760-2010) for the Loess Plateau and its possible driving mechanisms. Glob. Planet. Chang. 122, 82-88.

Dai, A., Trenberth, K.E., Karl, T.R., 1999. Effects of clouds, soil moisture, precipitation, and water vapor on diurnal temperature range. J. Clim. 12, 2451-2473.

Damgaard, C., Weiner, J., 2000. Describing inequality in plant size or fecundity. Ecology 81, 1139-1142.

Gao, Y., He, N., Wang, Q., Miao, C., 2013. Increase of external nutrient input impact on carbon sinks in Chinese coastal seas. Environ. Sci. Technol. 47, 13215-132156.

Gao, Y., Zhu, X., Yu, G., et al., 2014. Water use efficiency threshold for terrestrial ecosystem carbon sequestration in China under afforestation. Agric. For. Meteorol. 195-196. 32-37.

IPCC, 2012. A Special Report of Working Groups I and II of the Intergovernmental Panel on Climate Change: Managing the Risks of Extreme Events and Disasters to Advance Climate Change Adaptation: Summary for Policymakers. Cambridge University Press, Cambridge, UK.

Jawitz, J.W., Mitchell, J., 2011. Temporal inequality in catchment discharge and solute export. Water Resour. Res. 47, W00J14. http://dx.doi.org/10.1029/2010WR010197.

Kang, S., Zhang, L., Song, X., et al., 2001. Runoff and sediment loss responses to rainfall and land use in two agricultural catchments on the Loess Plateau of China. Hydrol. Process. 15, 977-988.

Kong, D., Miao, C., Borthwick, A.G.L., et al., 2015. Evolution of the Yellow River Delta and its relationship with runoff and sediment load from 1983 to 2011. J. Hydrol. 520, 157-167.

Lewis, S.C., Karoly, D.J., 2013. Evaluation of historical diurnal temperature range trends in CMIP5 models. J. Clim. 26, 9077-9089.

Li, Z., Zheng, F.L., Liu, W.Z., Flanagan, D.C., 2010. Spatial distribution and temporal trends of extreme temperature and precipitation events on the Loess Plateau of China during 1961-2007. Quat. Int. 226, 92-100.
Li, Z., Liu, W.Z., Zhang, X.C., Zheng, F.L., 2011. Assessing the site-specific impacts of climate change on hydrology, soil erosion and crop yields in the Loess Plateau of China. Clim. Chang. 105, 223-242.

Li, Z., Zheng, F.L., Liu, W.Z., Jiang, D.J., 2012. Spatially downscaling GCMs outputs to project changes in extreme precipitation and temperature events on the Loess Plateau of China during the 21st century. Glob. Planet. Chang. 82-83, 65-73.

Li, K., Yang, X., Mu, et al., 2013. The possible effects of global warming on cropping systems in China VII-the effects of climate change on planting boundaries of different winter-spring varieties of winter wheat in China. China Agric. Sci. 46, 1583-1594. http://dx.doi.org/10.3864/j.issn.0578-1752.2013.08.007.

Linderholm, H.W., 2006. Growing season changes in the last century. Agric. For. Meteorol. 137, 1-14.

Mann, H.B., 1945. Nonparametric tests against trend. Econometrica 13, 245-259.

Masaki, Y., Hanasaki, N., Takahashi, K., Hijioka, Y., 2014. Global-scale analysis on future changes in flow regimes using Gini and Lorenz asymmetry coefficients. Water Resour. Res. 50, 4054-4078.

Miao, C.Y., Ni, J.R., Borthwick, A.G.L., Yang, L., 2011. A preliminary estimate of human and natural contributions to the changes in water discharge and sediment load in the Yellow River. Glob. Planet. Chang. 76, 196-205.

Miao, C., Duan, Q., Sun, Q., Li, J., 2013. Evaluation and application of Bayesian multi-model estimation in temperature simulations. Prog. Phys. Geogr. 37, 727-744.

National Meteorological Information Center, 2012. Assessment Report of China's Surface Temperature $0.5 \times 0.5$ Gridded Dataset (V2.0). National Meteorological Information Center, Beijing.

Piao, S., Ciais, P., Huang, Y., et al., 2010. The impacts of climate change on water resources and agriculture in China. Nature 467, 43-51. http://dx.doi.org/10.1038/nature09364.

Qian, W., Fu, J., Yan, Z., 2007. Decrease of light rain events in summer associated with a warming environment in China during 1961-2005. Geophys. Res. Lett. 34, L11705. http://dx.doi.org/10.1029/2007GL029631.

Rajah, K., O'Leary, T., Turner, A., et al., 2014. Changes to the temporal distribution of daily precipitation. Geophys. Res. Lett. 41, 8887-8894. http://dx.doi.org/10.1002/ 2014GL062156.

Seekell, D.A., D'Odorico, P., Pace, M.L., 2011. Virtual water transfers unlikely to redress inequality in global water use. Environ. Res. Lett. 6, 024017. http://dx.doi.org/10.1088/ $1748-9326 / 6 / 2 / 024017$.

Sen, P.K., 1968. Estimates of the regression coefficient based on Kendall's tau. J. Am. Stat Assoc. 63, 1379-1389.

Shen, Y., Feng, M., Zhang, H., Gao, F., 2010. Interpolation methods of China daily precipitation data. J. Appl. Meteorol. Sci. 21, 279-286.

Shen, X., Liu, B., Li, G., et al., 2014. Spatiotemporal change of diurnal temperature range and its relationship with sunshine duration and precipitation in China. J. Geophys. Res. 119, 13163-13179.

Shi, H., Shao, M.G., 2000. Soil and water loss from the Loess Plateau in China. J. Arid Environ. 45, 9-20.

Sillmann, J., Kharin, V.V., Zhang, X., Zwiers, F.W., Bronaugh, D., 2013. Climate extremes indices in the CMIP5 multimodel ensemble: part 1. Model evaluation in the present climate. J. Geophys. Res. 118, 1716-1733.

Sun, Q., Miao, C., Duan, Q., et al., 2014. Would the 'real' observed dataset stand up? A critical examination of eight observed gridded climate datasets for China. Environ. Res. Lett. 9, 015001-015015.

Wang, H., Yang, Z., Saito, Y., et al., 2007. Stepwise decreases of the Huanghe (Yellow River) sediment load (1950-2005): impacts of climate change and human activities. Glob. Planet. Chang. 57, 331-354.

Wang, Y., Shao, M., Shao, H., 2010. A preliminary investigation of the dynamic characteristics of dried soil layers on the Loess Plateau of China. J. Hydrol. 381, 9-17.

Wang, Y., Shao, M., Zhu, Y., Liu, Z., 2011a. Impacts of land use and plant characteristics on dried soil layers in different climatic regions on the Loess Plateau of China. Agric. For. Meteorol. 151, 437-448.

Wang, Q.X., Fan, X.H., Qin, Z.D., Wang, M.B., 2012. Change trends of temperature and precipitation in the Loess Plateau Region of China, 1961-2010. Glob. Planet. Chang. 92-93, 138-147.

Wang, F., Zhang, C., Peng, Y., Zhou, H., 2014. Diurnal temperature range variation and its causes in a semiarid region from 1957 to 2006. Int. J. Climatol. 34, 343-354.

Wang, F., Mu, X., Li, R., et al., 2015. Co-evolution of soil and water conservation policy and human-environment linkages in the Yellow River Basin since 1949. Sci. Total Environ. 508, 166-177.

Williams, J.W., Jackson, S.T., Kutzbacht, J.E., 2007. Projected distributions of novel and disappearing climates by 2100 AD. Proc. Natl. Acad. Sci. U. S. A. 104, 5738-5742.

Zhang, X.C., Liu, W.Z., 2005. Simulating potential response of hydrology, soil erosion, and crop productivity to climate change in Changwu tableland region on the Loess Plateau of China. Agric. For. Meteorol. 131, 127-142.

Zhang, X.C., Nearing, M.A., 2005. Impact of climate change on soil erosion, runoff and wheat productivity in central Oklahoma. Catena 61, 185-195.

Zhou, X., Ding, Y., Wang, P., 2010. Moisture transport in the Asian summer monsoon region and its relationship with summer precipitation in China. Acta Metall. Sin. 24 31-42.

\section{Further reading}

Wang, Q., Fan, X., Wang, M., 2011b. Precipitation trends during 1961-2010 in the Loess Plateau region of China. Acta Ecol. Sin. 31, 5512-5523. 